\title{
Karakteristik Suhu Perairan di Kolam Budidaya Perikanan
}

Characteristics of Water Temperature in Aquaculture Pond

\author{
Muarif \\ E-mail: muarif2010@gmail.com
}

\begin{abstract}
The Fluctuation of water temperature in aquaculture pond is important, because water temperature affects biological and chemical processes and then which affect to growth and survival of aquaculture fish. The temperature range in this research have a range of $22-30^{\circ} \mathrm{C}$ is at a suitable for aquaculture. The pattern of changes of water temperature in aquaculture ponds present a high during the day, low in the morning and middle at noon. Statistical test results the water temperature in the morning, afternoon, and evening was significantly different.
\end{abstract}

Keywords: Water temperature, aquaculture, pond

\begin{abstract}
ABSTRAK
Pola perubahan suhu perairan pada kolam budidaya perikanan penting diketahui, karena suhu akan mempengaruhi proses biologi dan kimiawi yang selanjutnya akan mempengaruhi pertumbuhan dan kelangsungan hidup ikan yang dibudidayakan. Kisaran suhu pada kolam pernelitian memiliki kisaran $22-30^{\circ} \mathrm{C}$ berada pada nilai yang layak untuk pengembangan budidaya perikanan. Pola perubahan suhu perairan pada kolam budidaya menunjukkan pola yang tinggi pada siang hari, rendah pada pagi hari dan sedang pada siang hari. Hasil uji statistik menunjukkan suhu air pada pagi, siang, dan sore hari saling berbeda nyata.
\end{abstract}

Kata kunci: Suhu Perairan, budidaya perikanan, kolam

Karakteristik Suhu Perairan di Kolam Budidaya Perikanan

Muarif. 2016. Karakteristik Suhu Perairan di Kolam Budidaya Perikanan. Jurnal Mina Sains 2(2): 96101.

\section{PENDAHULUAN}

Suhu perairan merupakan salah satu faktor lingkungan penting yang dapat mempengaruhi produksi dalam usaha budidaya perikanan. Air akan mengatur pengendalian suhu tubuh organisme (Boyd 2015) dan pada umumnya ikan sensitif terhadap perubahan suhu air (Chin 2006; Parker 2012). Berbagai aktivitas penting biota air seperti pernapasan, konsumsi pakan, pertumbuhan, dan reproduksi akan dipengaruhi oleh suhu perairan (Bolorunduro \& Abdullah 1996).

Suhu perairan tidak bersifat konstan, akan tetapi karakteristiknya menunjukkan perubahan yang bersifat dinamis. Banyak faktor yang akan mempengaruhi suhu perairan sehingga nilainya akan berubah dari waktu ke waktu. Faktor-faktor yang mempengaruhi perubahan suhu di perairan adalah keberadaan naungan (misalnya pohon atau tanaman air), air buangan (limbah) yang masuk ke badan air (Chin 2006), radiasi matahari, suhu udara, cuaca, dan iklim (Boyd 2015).

Suhu akan mempengaruhi berbagai proses fisika dan kimia di perairan seperti densitas air, kelarutan gas, kelarutan senyawa, dan sifat senyawa beracun (Howerton, 2001; Boyd, 2015). Suhu perairan berpengaruh terhadap proses-proses biologi dan kimiawi (Boyd \& Lichtkopler 1979).

Suhu perairan pada kolam budidaya perikanan penting diteliti untuk mengetahui karakteristik pola perubahannya. Pola perubahan suhu tersebut akan berdampak 
langsung atau tidak langsung terhadap proses fisiologi yang selanjutnya akan mempengaruhi pertumbuhan dan kelangsungan hidup biota air yang dibudidayakan. Tujuan dari penelitian karakteristik suhu perairan ini adalah untuk mengetahui kisaran suhu perairan dan pola perubahannya di kolam budidaya perikanan. Penelitian karakteristik pola perubahan suhu perairan ini akan memberikan informasi tentang kisaran suhu dan pola perubahannya yang dapat menjadi masukan bagi pengelolaan budidaya perikanan. Pendekatan ini dapat menjadi strategi adaptif budidaya perikanan terhadap variasi suhu selama seiklus hidup ikan (Pang et al. 2016), .

\section{BAHAN DAN METODE}

Penelitian pola perubahan suhu perairan ini dilaksanakan di kolam budidaya perikanan Jurusan Perikanan Universitas Djuanda Bogor. Pengambilan data suhu perairan berlangsung pada tanggal 18 - 20 Oktober 2016.

Penelitian ini menggunakan pendekatan rancangan faktorial dengan perbedaan waktu pengukuran (pagi, siang, dan sore) sebagai perlakuan faktor pertama dan perbedaan hari sebagai perlakuan pada faktor yang kedua, Suhu perairan diamati setiap pagi, siang, dan sore hari selama tiga hari. Perbedaan waktu dan hari menjadi perlakuan dalam penelitian ini. Pengukuran suhu air dilakukan pada tiga kolam yang berperan sebagai ulangan.
Pengolahan data berupa tabulasi dan grafik. Analisis data menggunakan analisis statistik yaitu berupa analisis ragam (ANOVA) dan uji lanjut menggunakan uji Tukey dan LSD.

\section{Hasil}

\section{HASIL DAN PEMBAHASAN}

\section{Suhu Perairan Kolam Budidaya Perikanan}

Suhu perairan di kolam budidaya perikanan selama penelitian berkisar antara 22$30{ }^{\circ} \mathrm{C}$. Suhu terendah $\left(22{ }^{\circ} \mathrm{C}\right)$ diperoleh pada pagi di hari kedua pengamatan dan suhu tertinggi $\left(30{ }^{\circ} \mathrm{C}\right)$ diperoleh pada pengukuran siang di hari pertama dan kedua pengamatan. Hujan yang terjadi pada malam hari kedua diperkirakan mempengaruhi suhu yang rendah pada pagi hari kedua. Pada siang hari kedua dan ketiga cuaca panas sehingga diperoleh nilai suhu tertinggi, sedangkan pada siang hari ketiga cuaca mendung.

Pada umumnya nilai suhu air yang tinggi diperoleh pada waktu pengamatan siang dan suhu air yang rendah diperoleh pada waktu pengamatan pagi. Pada waktu pengamatan pagi nilai suhu air selama tiga hari berkisar antara 22-25 ${ }^{\circ} \mathrm{C}$. Pada waktu pengamatan siang nilai suhu air selama tiga hari berkisar antara 27$30{ }^{\circ} \mathrm{C}$. Suhu air pada sore hari berada pada nilai pertengahan antar suhu pagi dan siang hari, yaitu berkisar antara $24-28{ }^{\circ} \mathrm{C}$ (Tabel 1).

Tabel 1 Suhu perairan selama penelitian

\begin{tabular}{lcccccccccc}
\hline Faktor 1 (Waktu) & Pagi & Siang & Sore & Pagi & Siang & Sore & Pagi & Siang & Sore \\
\hline Faktor 2 (Hari) & Hari 1 & Hari 1 & Hari 1 & Hari 2 & Hari 2 & Hari 2 & Hari 3 & Hari 3 Hari 3 \\
\hline \multirow{4}{*}{ Ulangan } & K1 & 23 & 27 & 26 & 24 & 28 & 27 & 22 & 27 & 27 \\
& K2 & 24 & 27 & 27 & 24 & 27 & 27 & 24 & 28 & 24 \\
& K3 & 23 & 30 & 26 & 24 & 30 & 28 & 25 & 28 & 26 \\
\hline
\end{tabular}

Keterangan: K1=kolam 1, K2=kolam 2, dan K3=kolam 3

\section{Pola Perubahan Suhu Perairan}

Pola perubahan suhu perairan kolam budidaya berdasarkan waktu menunjukkan pola suhu rendah di pagi hari, meningkat di siang hari, dan menurun kembali di sore hari (Gambar 1). Hasil analisis ragam (ANOVA) diperoleh nilai sig $<0,05$ yang menunjukkan nilai suhu berbeda nyata berdasarkan waktu. Hasil uji lanjut menggunakan uji Tukey HSD dan uji LSD menunjukkan nilai sig $<0,05$ yang menunjukkan natra waktu pagi, siang, dan sore hari memiliki nilai suhu yang berbeda (Tabel 2). 


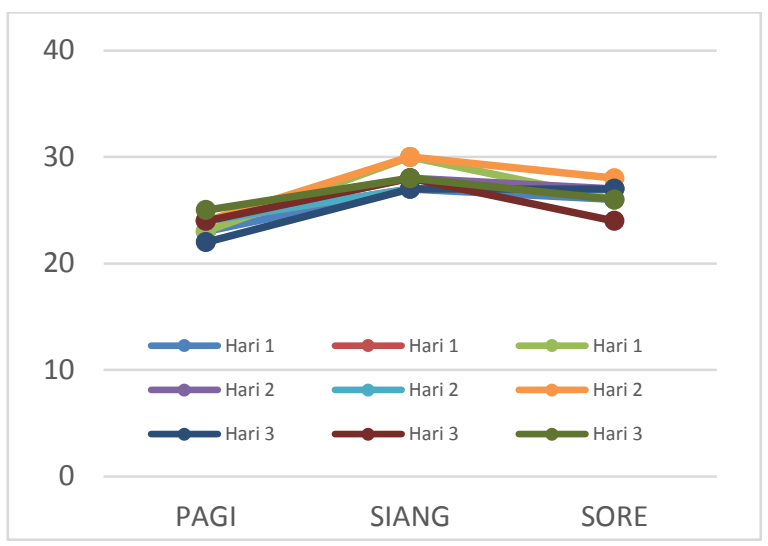

Gambar 1 Pola perubahan suhu berdasarkan waktu (pagi, siang, dan sore)

Tabel 2 Hasil uji lanjut (Tukey HSD dan LSD sebaran suhu pada waktu yang berbeda

\begin{tabular}{llcc}
\hline \multirow{2}{*}{$\begin{array}{c}\text { Perbandingan antar } \\
\text { waktu }\end{array}$} & \multicolumn{2}{c}{ Sig } \\
\cline { 3 - 4 } & & $\begin{array}{c}\text { Tukey } \\
\text { HSD }\end{array}$ & LSD \\
\hline Pagi & Siang & 0.000 & 0.000 \\
& Sore & 0.000 & 0.000 \\
Siang & Pagi & 0.000 & 0.000 \\
& Sore & 0.023 & 0.009 \\
Sore & Pagi & 0.000 & 0.000 \\
& Siang & 0.023 & 0.009 \\
\hline
\end{tabular}

Gambar 2 memperlihatkan pola sebaran suhu pada hari yang berbeda. Sebagian besar pengamatan tidak memperlihatkan perbedaan suhu pada hari 1 , hari 2, maupun hari 3. Hasil analisis ragam diperoleh nilai sig $=0,244$ (sig $>0,05$ ) yang mengindikasikan perubahan hari tidak memperlihatkan perbedaan suhu yang nyata. Hasil analisis ragam juga menunjukkan tidak ada interaksi antara waktu pengamatan dan hari pengamatan terhadap perubahan suhu (sig=0,849 atau sig $>0,05$ ).

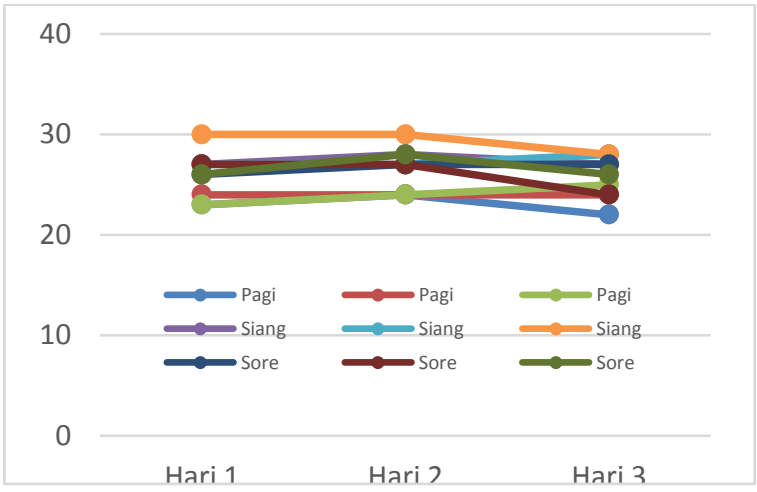

Gambar 2 Pola perubahan suhu pada hari yang berbeda 


\section{Pembahasan \\ Karakteristik Perubahan Suhu Perairan di Kolam Budidaya Perikanan}

Pola perubahan suhu perairan selama penelitian menunjukkan fluktuasi nilainya dipengaruhi oleh waktu (pagi, siang dan sore) (sig<0,05). Menurut Boyd (2015) radiasi matahari, suhu udara, cuaca, dan iklim akan mempengaruhi besarnya suhu perairan. Keberadaan nilai suhu perairan yang tinggi pada siang dibanding pagi dan sore mengindikasikan adanya peranan radiasi matahari. Menurut Lucas dan Southgate (2012) penetrasi sinar matahari membuat suhu meningkat tinggi pada kolam yang dangkal.

Pada saat turun hujan, suhu perairan akan rendah. Penurunan suhu tersebut disebabkan oleh tidak adanya radiasi matahari dan menurunnya suhu udara, sehingga hujan juga berperan mempengaruhi suhu di perairan (Parker 2012). Hal ini terbukti kondisi cuaca mendung dan hujan pada hari ketiga menyebabkan kisaran suhu pada hari tersebut lebih rendah dibanding hari lainnya.

\section{Keterkaitan Nilai Suhu Perairan dalam Budidaya Perikanan}

Tujuan yang ingin dicapai dalam setiap proses budidaya perikanan adalah produksi atau hasil panen ikan yang tinggi. Pada pembenihan ikan, aspek keberhasilan pemijahan (proses reproduksi) serta pertumbuhan dan kelangsungan hidup benih ikan adalah faktor yang menentukan tinggi rendahnya produksi benih ikan. Pada budidaya pembesaran ikan, produksi budidaya perikanan ditentukan oleh pertumbuhan dan kelangsungan hidup ikan yang dibudidayakan, untuk itu faktor-faktor yang mempengaruhi reproduksi, pertumbuhan dan kelangsungan hidup penting untuk diketahui. Suhu merupakan salah satu faktor yang mempengaruhi reproduksi ikan (Parker 2012), pertumbuhan (Stickney 2000) dan kelangsungan hidup ikan budidaya (Parker 2012). Oleh karena itu, suhu dinilai memainkan peranan penting dalam budidaya perikanan (Howerton 2001).

Proses fisiologi penting yang dipengaruhi oleh suhu diantaranya adalah reproduksi. Pada proses reproduksi, produksi dan pengeluaran hormon dikontrol oleh rangsangan lingkungan internal dan eksternal. Kondisi alam, perubahan iklim seperti hari yang cerah dan suhu berperan menjadi stimulus pengeluaran hormon tersebut (Parker 2012).

Keberhasilan proses pemijahan ikan, salah satunya juga ditentukan oleh suhu perairan.Penelitian Parker (2012) mendapatkan suhu berperan dalam mengontrol manipulasi waktu pemijahan ikan. Ikan catfish memijah pada suhu antara $23,9-29,4{ }^{\circ} \mathrm{C}$, sedangkan ikan Tilapia dapat memijah sepanjang tahun pada suhu perairan antara $25-30{ }^{\circ} \mathrm{C}$. Telur ikan catfish biasanya menetas 5-10 hari tergantung suhu air, dan pada suhu $25,6{ }^{\circ} \mathrm{C}$, telur menetas dalam waktu 8 hari. Pada proses penetasan telur ikan catfish, suhu perairan harus berada pada kisaran $23,9^{\circ} \mathrm{C}-27,8^{\circ} \mathrm{C}$.

Salah satu faktor yang mempengaruhi pertumbuhan ikan adalah suhu perairan (Stickney 2000; Nytrø et al. 2014). Pengaruh suhu terhadap pertumbuhan ikan berhubungan dengan sifat ikan yang poikilotermal (Parker 2012; Lucas dan Southgate 2012). Suhu perairan berpengaruh terhadap proses-proses biologi dan kimiawi. Pada umumnya kecepatan reaksi kimia dan biologi naik dua kali lipat setiap kenaikan suhu 10. Hal ini berarti pada suhu 30 dibanding 20 maka organisme perairan akan menggunakan oksigen dua kali lipat untuk mengimbangi reaksi kimia yang berjalan dua kali lebih cepat (Boyd \& Lichtkopler 1979). Semua fungsi tubuh termasuk pertumbuhan tergantung pada kecepatan metabolisme, sehingga pertumbuhan dipengaruhi juga oleh suhu lingkungan (Lucas $\&$ Southgate 2012). Pertumbuhan terbaik diperoleh pada saat suhu tubuh hewan akuatik mendekati suhu lingkungannya, karena energi yang biasanya dibutuhkan untuk mengatur suhu tubuh akan digunakan untuk pertumbuhan (Parker 2012).

Suhu air signifikan mempengaruhi konsumsi pakan (Parker 2012; De et al. 2016), konversi pakan, dan laju pertumbuhan harian (De et al. 2016). Ikan yang diaklimatisasi pada suhu $25{ }^{\circ} \mathrm{C}$ menunjukkan hasil yang lebih baik dibanding ikan yang diaklimatisasi pada suhu $15^{\circ} \mathrm{C}$, antara lain SGR (specific growth rate ) lebih tinggi 204\%, FR (feeding rate) lebih tinggi $97 \%$, dan FE (feed efficiency) lebih tinggi 46\% (Pang et al. 2016). 
Kelangsungan hidup ikan dipengaruhi oleh faktor internal (umur) dan faktor eksternal (predator, penyakit, dan kualitas air). Suhu merupakan faktor eksternal yang dapat mempengaruhi kelangsungan hidup ikan secara langsung. Ikan akan mati apabila suhu perairan berada di luar batas minimum atau maksimum yang dapat ditolerir oleh ikan. Ikan juga akan mati apabila terjadi perubahan suhu yang mendadak (Boyd \& Lichtkopler 1979). Menurut Parker (2012) aktivitas ikan biasanya menurun pada suhu dibawah $20^{\circ} \mathrm{C}$. Ikan Tilapia tidak dapat bertahan pada suhu dibawah $10{ }^{\circ} \mathrm{C}$. Ikan Tilapia menunjukkan subletal dibawah suhu 10-15,6 ${ }^{\circ} \mathrm{C}$ memungkinkan berkembangnya infeksi oleh jamur. Suhu ideal untuk pertumbuhan ikan Tilapia adalah antara $26,1^{\circ}$ dan $32,2^{\circ} \mathrm{C}$.

Secara tidak langsung suhu juga dapat mempengaruhi kelangsungan hidup ikan sepertinya menurunnya daya tahan (imunitas) tubuh ikan pada suhu yang tidak ideal. Sebagai contoh Parker (2012) mendapatkan pada suhu di bawah $12,2^{\circ} \mathrm{C}$ ikan Tilapia kehilangan daya tahannya terhadap penyakit dan serangan bakteri, jamur, dan parasit.

Nilai kisaran suhu perairan selama penelitian $\left(22-30{ }^{\circ} \mathrm{C}\right)$ tergolong baik untuk budidaya perikanan. Arula et al. (2015) berpendapat pertumbuhan ikan yang tinggi diperoleh pada suhu diatas $18^{\circ} \mathrm{C}$. Parker (2012) berpendapat bahwa secara umum ikan-ikan air tawar pada daerah hangat berkembang baik pada suhu diatas $21,1^{\circ} \mathrm{C}$. Menurut Bolorunduro dan Abdullah (1996) suhu perairan pada kisaran $25-32{ }^{\circ} \mathrm{C}$ sangat sesuai untuk budidaya ikan. Boyd dan Lichtkopler (1979) menguatkan pendapat tersebut dengan menyatakan pertumbuhan ikan bagus pada suhu prairan $25-32{ }^{\circ} \mathrm{C}$. De et al. (2016) mengemukaan pendapat yang sedikit berbeda dengan menyatakan suhu 26 and $30{ }^{\circ} \mathrm{C}$ adalah suhu air yang optimum untuk budidaya perikanan.

Keberadaan suhu yang berperan penting mempengaruhi berbagai proses biologi dan kimiawi dalam tubuh ikan, menjadikan pengelolaan suhu perairan harus menjadi perhatian utama (Parker 2012). Air yang digunakan untuk pemeliharaan larva biasanya perlu dilakukan treatmen suhu untuk mengkondisikan suhu yang optimal (Lucas dan Southgate 2012).

\section{Peranan Suhu Perairan terhadap Kualitas Air lainnya}

Kualitas air tergantung pada faktor internal dalam kolam seperti suhu (Lucas dan Southgate 2012). Parameter kualitas air yang mendapatkan pengaruh akibat perubahan suhu diantaranya adalah kelarutan gas. Hubungan kelarutan gas dengan suhu dijelaskan sebagai berikut: tingkat kelarutan oksigen menurun dengan meningkatnya suhu (Chin 2006; Parker 2012). Selain menurunnya tingkat kelarutan oksigen, pada saat suhu meningkat aktivitas metabolisme pada organisme perairan juga akan meningkat dan hewan akan menggunakan oksigen dua kali lipat lebih banyak. Untuk itu kondisi kritis di perairan tropis ditetukan oleh suhu dan oksigen terlarut (Boyd \& Lichtkopler 1979) (Howerton 2001). Sifat gas lainnya yang dipengaruhi oleh suhu adalah proporsi gas $\mathrm{H}_{2} \mathrm{~S}$ dan $\mathrm{NH}_{3}$. Proporsi $\mathrm{H}_{2} \mathrm{~S}$ menurun dengan meningkatnya suhu, sedangkan proporsi $\mathrm{NH}_{3}$ meningkat dengan meningkatnya suhu (Howerton 2001; Boyd 2015).

Selain kelarutan gas, kelarutan senyawa di air juga dipengaruhi oleh suhu. Boyd (2015) menjelaskan bahwa peningkatan suhu perairan akan menaikan kelarutan senyawa di air. Pada senyawa yang bersifat toksik, maka daya racun senyawa tersebut pada umumnya meningkat dengan meningkatnya suhu. Untuk itu pada kondisi terjadi peningkatan suhu keberadaan senyawa beracun wajib diwaspadai.

Kondisi kualitas air lainnya yang dipengaruhi suhu adalah proses nitrifikasi juga mendapat pengaruh dari suhu perairan, hal ini berhubungan dengan pertumbuhan dan respirasi bakteri yang dipengaruhi oleh suhu (Boyd 2015). Menurut Boyd (2015) proses nitrifikasi berlangsung cepat pada suhu 25$35{ }^{\circ} \mathrm{C}$, sedangkan menurut Chin (2006) suhu optimum untuk proses nitrifikasi adalah antara 20-25 ${ }^{\circ} \mathrm{C}$, dimana laju nitrifikasi akan rendah apabila suhu kurang dari nilai optimum.

Analisis keterkaitan nilai suhu selama penelitian dengan perannya dalam mempengaruhi kualitas air lainnya, dinilai kisaran dan besarnya perubahan suhu perairan dalam penelitian ini memberikan pengaruh yang aman bagi perubahan kualitas air kolam. 
Nilai suhu dalam penelitian ini berada pada kisaran yang ideal untuk kinerja bakteri, sehingga keberadaan gas-gas beracun akan minimalis di perairan ini.

\section{KESIMPULAN}

Suhu perairan selama penelitian berada pada kisaran nilai yang sesuai untuk kegiatan budidaya perikanan. Suhu perairan di kolam budidaya perikanan berbeda nyata pada waktu pada waktu pagi, siang, dan sore hari. Suhu perairan memiliki keterkaitan yang kompleks terhadap reproduksi, pertumbuhan, kelangsungan hidup ikan, dan juga terhadap kualitas air lainnya yang akan mempengaruhi produksi budidaya perikanan, sehingga pemantauan dan pengelolaan suhu perairan penting dalam proses budidaya perikanan.

\section{UCAPAN TERIMA KASIH}

Ucapan terimakasih disampaikan kepada mahasiswa Jurusan Perikanan Universitas Djuanda Angkatan 2014 (Aris, Retno, Arif, Sidik, Ridho, Deni, Anjas, Pawly, Agung, Destiana, Karwati, Laili, Gilang, Irwan, dan Ganjar) yang telah membantu pengambilan data penelitian.

\section{DAFTAR PUSTAKA}

Arula T. et al. 2015. Estuarine, Coastal and Shelf Science Dual impact of temperature on growth and mortality of marine fi sh larvae in a shallow estuarine habitat. Estuarine, Coastal and Shelf Science 167:326-335. Available at: http://dx.doi.org/10.1016/j.ecss.2015.10.0 04.

Bolorunduro PI, Abdullah AY. 1996. Water Quality Management in Fish Culture. Fisheries Series 3(98): 36.

Boyd CE. 2015. Water Quality. Switzerland: Springer.
Boyd CE, Lichtkopler F. 1979. Water Quality Mngt in Pond Fish Culture. Alabama: Auburn University.

Chin DA. 2006. Water-Quality Engineering in Natural Systems. New Jersey: John Wiley \& Sons, Inc.

De M. et al. 2016. Effect of temperature and diet on growth and gastric emptying time of. Aquaculture Reports 4 ;118-124. Available at: http://dx.doi.org/10.1016/j.aqrep.2016.08. 002.

Howerton R. 2001. Best Management Practices for Hawaiian, Hawaii: Center for Tropical and Subtropical Aquaculture.

Lucas JS, Southgate PC. 2012. Aquaculture Farming Aquatic Animals and Plants. Oxford: Blackwell Publishing Ltd.

Pang X, Fu S, Zhang Y. 2016. Comparative Biochemistry and Physiology, Part A Acclimation temperature alters the relationship between growth and swimming performance among juvenile common carp ( Cyprinus carpio ). Comparative Biochemistry and Physiology, Part A, 199, pp.111-119. Available at: http://dx.doi.org/10.1016/j.cbpa.2016.06.0 11.

Parker R. 2012. Aquaculture Science. New York: Delmar.

Stickney RR. 2000. Encyclopedia of Aquaculture. Texas: A Wiley-Interscience Publication. 